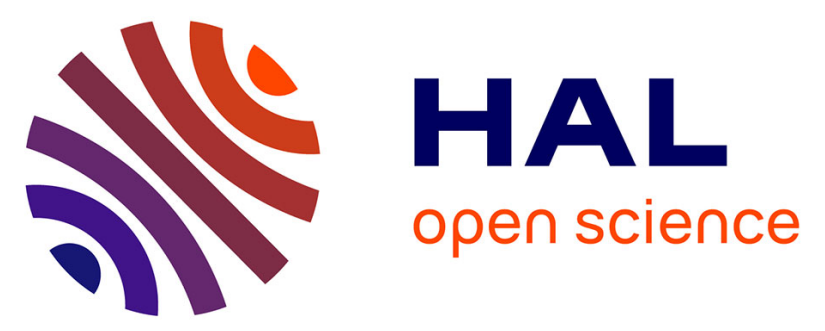

\title{
Heterogeneous Catalysis as a Tool for Production of Aromatic Compounds From Lignin
}

\author{
Awan Iqra Zubair, Nathalie Tanchoux, Françoise Quignard, Stefania \\ Albonetti, Fabrizio Cavani, Francesco Di Renzo
}

\section{- To cite this version:}

Awan Iqra Zubair, Nathalie Tanchoux, Françoise Quignard, Stefania Albonetti, Fabrizio Cavani, et al. Heterogeneous Catalysis as a Tool for Production of Aromatic Compounds From Lignin. Stefania Albonetti; Siglinda Perathoner; Elsye Alessandra Quadrelli. Horizons in Sustainable Industrial Chemistry and Catalysis, 178, Chapter 13, 2019, Studies in Surface Science and catalysis, SSC B9780-444-64127-4.00013-6, 00013. hal-01967393

\section{HAL Id: hal-01967393 \\ https://hal.science/hal-01967393}

Submitted on 31 Dec 2018

HAL is a multi-disciplinary open access archive for the deposit and dissemination of scientific research documents, whether they are published or not. The documents may come from teaching and research institutions in France or abroad, or from public or private research centers.
L'archive ouverte pluridisciplinaire HAL, est destinée au dépôt et à la diffusion de documents scientifiques de niveau recherche, publiés ou non, émanant des établissements d'enseignement et de recherche français ou étrangers, des laboratoires publics ou privés. 


\section{AUTHOR QUERY FORM}

\begin{tabular}{|c|c|c|}
\hline 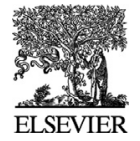 & $\begin{array}{l}\text { Book: Studies in Surface Science and } \\
\text { Catalysis } \\
\text { Chapter Number: } 13\end{array}$ & $\begin{array}{l}\text { Please e-mail your responses and any corrections to: } \\
\text { E-mail: omer.m@elsevier.com }\end{array}$ \\
\hline
\end{tabular}

Dear Author,

Please check your proof carefully and mark all corrections at the appropriate place in the proof (e.g., by using onscreen annotation in the PDF file) or compile them in a separate list. Note: if you opt to annotate the file with software other than Adobe Reader then please also highlight the appropriate place in the PDF file. To ensure fast publication of your paper please return your corrections within 48 hours.

For correction or revision of any artwork, please consult http://www.elsevier.com/artworkinstructions.

We were unable to process your file(s) fully electronically and have proceeded by

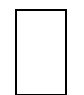

Scanning (parts of) your article

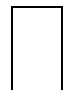

Rekeying (parts of) your article

Scanning the artwork

Any queries or remarks that have arisen during the processing of your manuscript are listed below and highlighted by flags in the proof. Click on the ' $\underline{Q}$ ' link to go to the location in the proof.

\begin{tabular}{|c|c|}
\hline $\begin{array}{l}\text { Location in } \\
\text { Chapter }\end{array}$ & $\begin{array}{l}\text { Query / Remark: click on the Q link to go } \\
\text { Please insert your reply or correction at the corresponding line in the proof }\end{array}$ \\
\hline$\underline{\text { Q1 }}$ & $\begin{array}{l}\text { Please check whether the suggested running head "Heterogeneous Catalysis" is appropriate for this } \\
\text { chapter. }\end{array}$ \\
\hline$\underline{\text { Q2 }}$ & $\begin{array}{l}\text { Per guidelines, affiliations should appear in English language. Hence, please check and update the } \\
\text { affiliation " } \dagger \text { ". }\end{array}$ \\
\hline$\underline{\text { Q3 }}$ & $\begin{array}{l}\text { The sentence that begins, "Mathias and Rodrigues in } 1995 \text { described the classical state of the art..." } \\
\text { seems incongruous. If it's classical, can it be state of the art? }\end{array}$ \\
\hline$\underline{\text { Q4 }}$ & $\begin{array}{l}\text { Please check if the insertion of Table } 13.2 \text { citation is OK, or suggest an alternative location if } \\
\text { necessary. }\end{array}$ \\
\hline$\underline{\text { Q5 }}$ & Please supply the name of the city of publication for Ref. [16]. \\
\hline$\underline{\text { Q6 }}$ & Please provide missing Ref. [39]. \\
\hline$\underline{\text { Q7 }}$ & Please provide better quality figure. \\
\hline
\end{tabular}




\begin{tabular}{|c|c|}
\hline \multirow[t]{2}{*}{$\underline{\text { Q8 }}$} & Please provide better quality figure. \\
\hline & $\begin{array}{l}\text { Please check this box or indicate your approval if } \\
\text { you have no corrections to make to the PDF file }\end{array}$ \\
\hline
\end{tabular}

Thank you for your assistance. 


\section{H A P T E R}

Weterogeneous Catalysis as a ToOI

\section{3} for Production of Aromatic Compounds From Lignin

Iqra Zubair Awan*, ${ }^{*}$, Nathalie Tanchoux ${ }^{\dagger}$, Françoise Quignard ${ }^{\dagger}$, Stefania Albonetti*, Fabrizio Cavani*, Francesco Di Renzo ${ }^{\dagger}$

*Department of Industrial Chemistry “Toso Montanari”, University of Bologna, Bologna, Italy 'Institut Charles Gerhardt, UMR5253 UM-CNRS-ENSCM, Montpellier, France

\section{O U T L I N E}

1 Introduction

1.1 The Potential of Lignin

1.2 The Challenges of Lignin

2 Lignin Model Molecules

$2.1 \beta$-O-4 Model Molecules

$2.2 \mathrm{C}-\mathrm{C}$ Linkage Model Molecules

2.3 Phenylcoumaran Model Molecules

$2.4 \alpha-\mathrm{O}-4$ and 4-O-5 Linkages Model Compounds

3 Lignin Depolymerization Strategies

4 Homogeneous Catalysis for Lignin Depolymerization
4.1 Base-Catalyzed Depolymerization

4.2 Acid-Catalyzed Lignin Depolymerization

4.3 Oxidative Lignin Depolymerization

5 Heterogeneous Catalysis for Lignin

Depolymerization

5.1 Catalytic Pyrolysis

5.2 Reductive Transformations

5.3 Oxidative Transformations

56 Economical Aspects of Lignin

Valorization

References

7 
2

s0010

p0010 The perspective depletion of fossil fuels and the need to control emissions of greenhouse gases has provoked research in finding alternative renewable resources. Among them, lignocellulose is a largely underutilized form of natural biomass, not directly competing with food resources. However, the difference in structure, composition and complexity of biomass as compared with crude oil requires an extensive reevaluation and rethinking of feedstock processing strategies to render economically viable the proposed transition to a bio-based industry $[1,2]$.

p0015 Lignocellulosic biomass is essentially composed of three components: cellulose $(38 \%-50 \%)$, hemicellulose $(23 \%-32 \%)$, and lignin $(15 \%-25 \%)$. Cellulose is currently hydrolyzed to glucose and converted into valuable products, such as ethanol biofuel, and platform chemicals, such as levulinic and formic acids, gamma-valerolactone, and derived products. Hemicellulose has potential applications for biofuel production, and for the generation of valuable chemicals intermediates, such as furfural. Lignin is the most underutilized fraction of lignocellulose. The total lignin availability in the biosphere exceeds 300 billion tons and annually increases by around 20 billion tons [3]. Annually, 40-50 million tons of roughly isolated lignin are available as waste of the pulp and paper industry and biorefineries. Only approximately $2 \%$ of the lignin available is commercially exploited while the remainder is burnt as a low-value fuel in the lignocellulose fractionation units [4].

\subsection{The Potential of Lignin}

Lignin is an important component of second- p0020 ary cell wall of plants, which forms a matrix between cellulose fibrils and provides mechanical strength and chemical protection to the plant. Lignin is a tridimensional amorphous polymer composed of three types of propylphenyl monolignols (Fig. 13.1), differing by their degree of substitution: sinapyl alcohol (S), coniferyl alcohol $(\mathrm{G})$, and p-coumaryl alcohol (H) units (see Fig. 13.1).

According to the source from which it derives, p0025 lignin presents a high diversity of chemical structure, not only in terms of percentage of each monolignol, but also from the different ways the building blocks are connected to each other through various crosslinked $\mathrm{C}-\mathrm{O}$ and $\mathrm{C}-\mathrm{C}$ bonds, including $\beta-\mathrm{O}-4, \beta-5, \beta-\beta, 4-\mathrm{O}-5,5-5$, or $\beta-1$ to form a complex matrix (see Fig. 13.2) [5]. Generally softwood has $45-48 \mathrm{wt} . \%$ and hardwood has $60 \mathrm{wt} . \%$ of $\beta-\mathrm{O}-4$ aryl glycerol ether bonds. Softwood has approximately $5 \mathrm{wt} . \%$ and hard wood has $0-2 \mathrm{wt} . \%$ of dibenzodioxocin $5-5^{\prime}-\alpha, \beta-\mathrm{O}-4^{\prime}$ bonds. In addition, softwood has $3.5-8 \mathrm{wt} . \%$ and hardwood has $6-9 \mathrm{wt} . \%$ of<smiles>COc1cc(/C=C/CO)ccc1OCC(C)OCCO</smiles>

f0010 FIG. 13.1 Monolignols, the building units of lignin. 


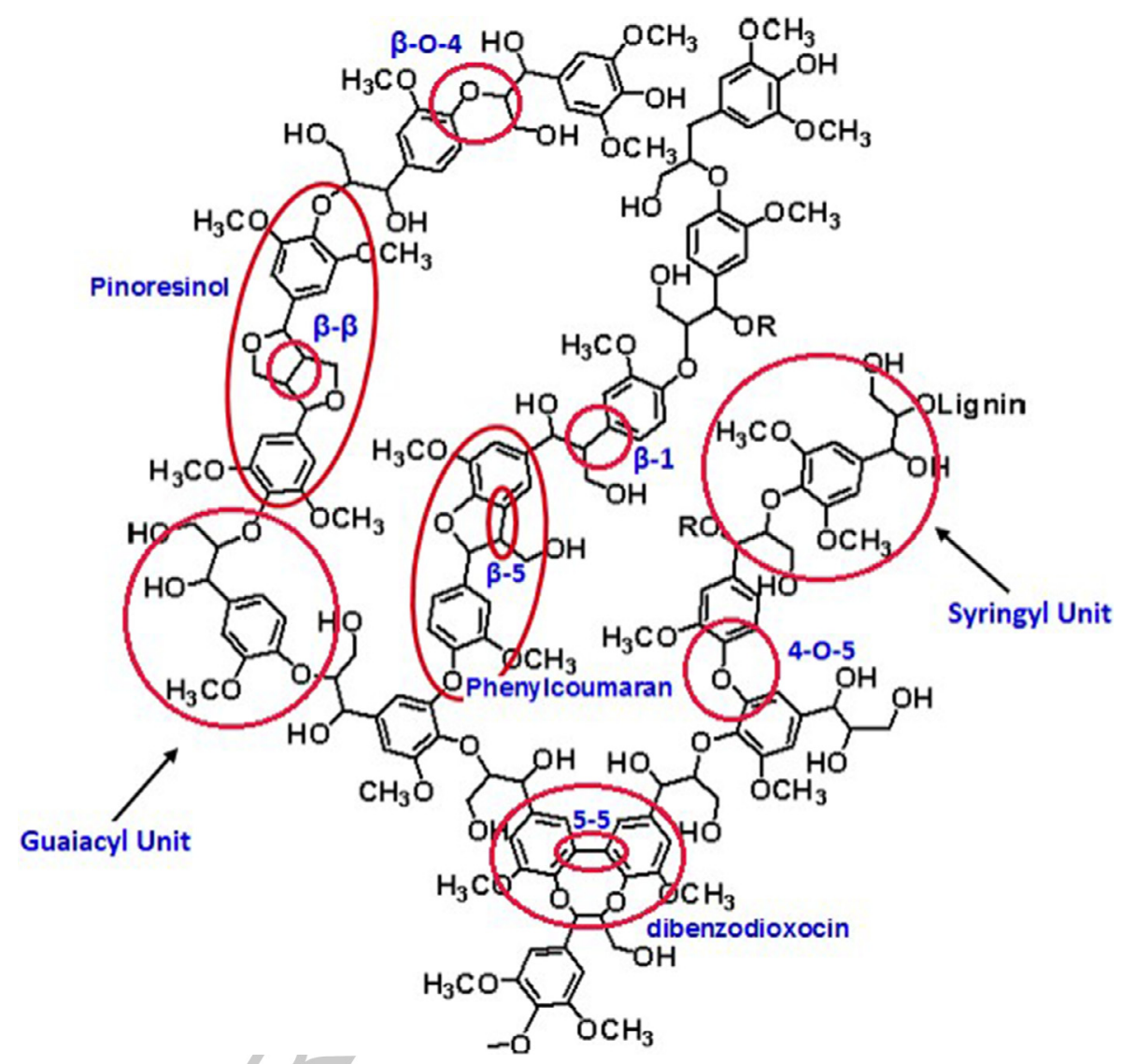

FIG. 13.2 Idealized structure of lignin with the most representative functional groups.

diphenyl ether 5-O-4' linkages [6,7]. The presence of these propylphenolic groups is at the basis of the interest for lignin, as a large reservoir of aromatic hydrocarbons and fine and specialty chemicals [8].

\section{s0020 1.2 The Challenges of Lignin}

p0030 Ultrasformed lignin finds property-based applications as components of epoxy glues for wood and packages, as fillers for bitumen and oil drilling fluids, or as a precursor of carbon fibers [9]. Considering the rich chemical functionalities of lignin, it is really promising to develop methods of depolymerization for the production of phenolic monomers for the polymer, flavor, and pharmaceutical industries [10]. Development of effective catalytic processes is badly needed in lignin depolymerization to orient the selectivity toward well-defined monomers, in order to minimize the separation costs, which can nullify the economic viability of depolymerization.

In order to tailor processes for the chemical p0035 valorization of lignin, a considerable challenge is to interpret the exact structural arrangement in the macromolecule. The structure of native lignin is only accessible by analysis of its hydrolysis products, which nature depends on the separation process used. Moreover, the 
4

13. HETEROGENEOUS GATALYSIS,

variability of lignin coming from different plant species hinders the developments of set protocols for lignin depolymerization. To cope with lignin's chemical complexity, a multifaceted, translational approach is required, which includes new analytical tools for structure characterization of substrates and products. The lignin depolymerization technology is still in the early phases of R\&D. Taking advantage of lignin as a reliable alternate source to fossil resources relies on the interest from game-changing investors, which will provide funding options when the depolymerization technology will reach a sufficient level of maturity [5].

\section{LIGNIN MODEL MOLECULES}

p0040 The complexity and variability of the structure of lignin has complicated the study of industrial lignin as a substrate. This fact has prompted the reliance on simplified, low molecular weight lignin model compounds to study lignin depolymerization. The basic advantage of these models is that they mimic the linkages present in the real lignin polymer, which helps in a better understanding of the breaking mechanisms of specific bonds. Furthermore, similar molecules are often present in the lignin degradation streams, after the depolymerization of lignin itself. The small compounds generated by fragmentation of lignin model compounds could be separated by chromatographic techniques, and further identification is possible using conventional analytical methods like GC-MS and NMR. Therefore, better and reliable characterization can be done because often only one type of linkage is present in the model molecule, which helps in understanding the reaction paths and the catalytic performance.

p0045 Catalytic systems can be studied in detail on oligomers and dimers aiming to understand the reactivity and selectivity of multifunctional group models. This is often the first step of research in lignin valorization. Considering the solubility and polyfunctionality of native lignin, as well as the repolymerization with an intermediate, demand a further step in the research planning. Different molecules are used as model compounds for different bonds of native lignin (see Fig. 13.3).

\section{1 ß-O-4 Model Molecules}

It is the most abundant linkage found in lig- p0050 nin. The ether bond is readily cleaved; indeed, the cleavage of these bonds during alkaline pulping constitutes the principle pathways in which the lignin is depolymerized and generates monomers with a phenyl propane structure.

The fragmentation of these linkages tends to p0055 lead to the generation of water-soluble oligomers containing phenolic hydroxyl groups [11]. The disruption of $\beta$-O-4-containing model molecules results in simpler analogs of the coumaryl, coniferyl, and sinapyl alcohols of monolignols (see Fig. 13.1). Secondary products obtained during the fragmentation include 3-hydroxypropaldehyde and arenes, with various aldehyde or alkyl side chains [12]. Successive oxidation reactions of coniferyl alcohol form vanillin, or lead to oxidation of the aromatic ring and form quinones (see Fig. 13.4 for possible lignin depolymerization products).

\subsection{C-C Linkage Model Molecules}

The C $-\mathrm{C}$ linkage in the lignin/model mole- p0060 cules are the hardest to break. Although carboncarbon linkages are present in the native lignin polymer, additional carbon-carbon bonds can be formed during lignin pretreatment, such as in alkali-promoted condensation reactions during kraft pulping [11]. The development of catalysts capable of performing these disruptions (particularly the aryl-aryl linkages) is therefore a considerable challenge that has not yet been adequately addressed. Model compounds with 
<smiles>[Z9]Cc1ccc(O[C@H](CO)C([R])c2ccc(OCC)c(OC)c2)c(OC)c1</smiles><smiles>[2H]c1ccc(C2Oc3c(OC)cc(CC)cc3[C@@H]2CO)cc1OC</smiles><smiles>COc1ccc(C(C)O)cc1OC</smiles><smiles>CCOc1ccc(C(CO)CO)cc1OC</smiles><smiles>CCOc1c(OC)cc(CC)cc1-c1cc(CC)cc(OC)c1OCC</smiles><smiles>CCOc1ccc(O[14c]2cc(CC)cc(OC)c2O)cc1OC</smiles>

FIG. 13.3 The main linkages in the lignin structure: $\beta-O-4$ (A), $\beta-5$ and $\alpha-O-4$ (B), $\beta-4$ (C), $5-5$ (D), $\beta-\beta$ (E), $4-\mathrm{O}-5$ (F).

these linkages usually involve dimeric arenes, with varying methoxy and hydroxyl substituents on the arene, which resemble dimers of $p$ coumaryl or coniferyl alcohols.

\section{s0040 2.3 Phenylcoumaran Model Molecules}

The $\beta-5$ linkage is often located in a fivemembered oxygenated ring fused with an aromatic ring in a coumaryl structure. In the model molecules, the rupture of both of these bonds often yields monomers such as vanillin and vanillic acid. Because of the inherent complexity in selectively disrupting both bonds, products resulting from the disruption of only one bond (i.e., the R-O-4 ether linkage) leaves compounds containing isolated $\beta-5$ linkages. In some instances, the $\beta-5$ bond remains intact and products resulting from the oxidation of the arene ring are observed [7].

\section{$2.4 \alpha-\mathrm{O}-4$ and 4-O-5 Linkages Model Compounds}

Compounds containing $\alpha-\mathrm{O}-4$ have also been p0070 observed in the lignin network, however, modern NMR experiments do not confirm the presence of noncyclic $\alpha-\mathrm{O}-4$ moieties [7]. 
6 13. HETEROGENEOUS CATALYSIS
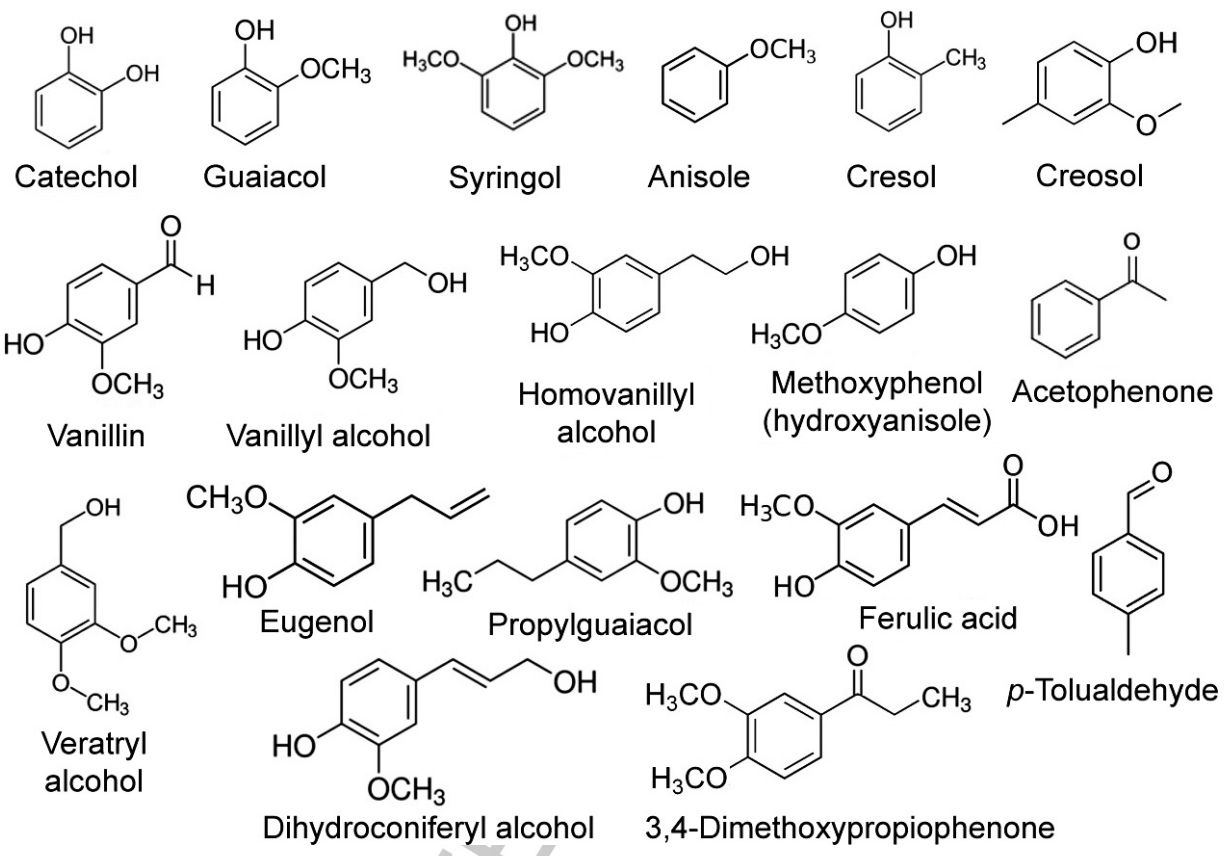

FIG. 13.4 Common monomers to be familiar with in lignin chemistry.

p0075 The 4-O-5 aryl-aryl ether linkage is, however, present in lignin mainly as the result of demethoxylating oligomer-oligomer couplings and leads to branching of the polymer. Some model compounds have been studied in order to understand the chemistry of this particular linkage as well.

\section{LIGNIN DEPOLYMERIZATION STRATEGIES}

p0080 Catalysts are essential to facilitate energy and atom-efficient lignin depolymerization and to selectively deoxygenate the products for further applications. Considerable efforts have been devoted to this field, but current methodologies are not satisfactory from the economical or environmental viewpoint. There are generally three main approaches for depolymerization: thermochemical (pyrolysis), biochemical, and chemical processes. In this chapter, we will deal essentially with the latter class of processes, under the aspects of hydrolysis, oxidation, and reduction. Pyrolysis refers to the thermal treatment of biomass/lignin in the absence of oxygen, with or without any catalysts at temperature between $300^{\circ} \mathrm{C}$ and $600^{\circ} \mathrm{C}[3,13]$. The cleavage of $\mathrm{OH}$ functional group linked to the aliphatic side chain, the breaking of alkyl side chain, aryl ether bonds, and linkage between aromatic ring occur when the temperature increases, forming a mixture of phenol, guaiacol, syringol, and catechols. Cracking of the aromatic ring occurs at temperatures above $500^{\circ} \mathrm{C}[13,14]$. The process is poorly selective and is affected by several factors including feedstock type, heating rate, and reaction temperature [15]. Biochemical methods have also been employed for the depolymerization but, despite interesting selectivities and mild conditions required, the time to grow the microorganisms/fungi and dilution of the system can make the process slow and less efficient [16]. In the chemical conversion, ether bonds $\mathrm{C}-\mathrm{O}-\mathrm{C}$ 
are targeted. Compared with thermochemical and biochemical processes, the chemical treatment of lignin has shown reliable results in terms of high selectivity and reaction control, with efficient valorization of lignin into functionalized aromatics.

p0085 The development of selective and robust catalysts must be a core effort in a biorefinery program. While selecting the catalytic route, there are two main considerations:

00010 1. Maximization of activity and selectivity of the catalyst under the chosen conditions (as mild as possible), bearing in mind the bulky nature of biomass source and the reaction conditions

o0015 2. Repolymerization and self-condensation capability of lignin under processing conditions, due to the formation of radicals and / or C $-\mathrm{C}$ bonds through selfcondensation reactions, which eventually leads to a complex pool of re-condensed aromatics [1].

p0100 The accountability of successful industrial scale production of chemicals is based on the selection of optimized reaction conditions. These include the chemical, engineering, and financial aspects of a feasible reaction. This chapter outlines the major pathways of lignin depolymerization, which can directly affect the reaction mechanisms controlling the nature and yield of valuable products. For the chemical depolymerization of lignin, a choice to be made among homogeneous and heterogeneous catalysis is on the top of the list.

\section{HOMOGENEOUS CATALYSIS FOR LIGNIN DEPOLYMERIZATION}

\section{s0060 4.1 Base-Catalyzed Depolymerization}

p0105 Lignin depolymerization through basecatalyzed hydrolysis is a well-known and straightforward route for the production of monomeric substituted phenols. The mineral bases used as catalysts, such as $\mathrm{NaOH}, \mathrm{KOH}$, and sometimes $\mathrm{LiOH}$, are cheap and commercially available but require corrosion-resistant materials and treatment of waste sewage. Typically, reflux boiling of lignosulfonates in $12 \% \mathrm{NaOH}$ solutions in nitrogen atmosphere provided up to $7 \%$ yields of highvalue added vanillin [17]. The reaction proceeds with cleavage of alkyl-aryl ether bonds, including $(\beta-\mathrm{O}-4)$, which is considered to be the weakestbond in the lignin structure $[13,18]$. However, in the basecatalyzed lignin hydrolysis reactions, the selectivity and yield are chiefly dependent on temperature, concentration and nature of the base, time, pressure, and the lignin/solvent ratio [19]. Beauchet et al. worked on base-catalyzed depolymerization reactions on less reactive Kraft lignin using $\mathrm{NaOH}$ as a base catalyst [20]. Total yield of identified monomers reached a maximum of $8.4 \mathrm{wt} . \%$ at $315^{\circ} \mathrm{C}$. Although the base-catalyzed process was simple, it needed to be carried out at a high temperature, and the control of selectivity was still difficult. The production of monomers is favored by high temperature and longer reaction time. The final yield is effectively decreased due to the formation of solid residues by the condensation reaction of intermediates and products. In base-catalyzed reactions, control of the rate of re-polymerization and condensation is the key challenge [3]. This fact is supported by the studies of Lercher and coworkers who carried out base-catalyzed liquidphase hydrolysis of organosolv lignin at $300^{\circ} \mathrm{C}$ and $25 \mathrm{MPa}$ using $\mathrm{NaOH}$ as a catalyst [21]. Syringol (4.1wt.\%), hydroxyacetophenone (1.6wt.\%), and guaiacol $(1.1 \mathrm{wt} . \%)$ were the major products of base-catalyzed hydrolysis and that oligomers form as secondary products. Oligomerization and polymerization of these highly reactive products, however, limit the amount of obtainable low-molecular-weight phenolic products. The inhibition of parasite oligomerization reactions is crucial to ensure a high yield of monomeric products. For analytical purposes this can be achieved by using a capping agent, such as boric acid, to suppress addition and condensation reactions of initially formed products [21]. 
8

\section{s0065 4.2 Acid-Catalyzed Lignin Depolymerization}

p0110 Early attempts of acid-catalyzed lignin hydrolysis dates back to the 1920s when Hagglund and Bjorkman distilled lignin with $12 \%$ $\mathrm{HCl}$ and observed severe repolymerization of the products [22]. The hydrolytic cleavage of $\alpha$ - and $\beta$-aryl ether linkages plays a main role in the acid-catalyzed hydrolysis because arylaryl ether bonds, phenolic $\mathrm{C}-\mathrm{O}$ bonds, and $\mathrm{C}-\mathrm{C}$ bonds between aromatic lignin units are relatively more stable and difficult to break.

p0115 Better stabilization of depolymerization products were later obtained in aqueous solutions of organic solvents, where acid-catalyzed hydrolysis was combined with hydrodeoxygenation of the products by hydrogen transfer from hydroxyl-bearing solvents. Hewson and Hibbert studied an acid-catalyzed treatment on maple wood meal by combinations of various acids and alcohols including $\mathrm{HCl}$ /ethanol and formic acid/ethylene glycol systems, with the purpose of separating the lignin into water-soluble and water-insoluble components [23]. The low range of temperature $\left(78-200^{\circ} \mathrm{C}\right)$ was moderately effective for the degradation of complex lignin into monomers. Later, high temperature conditions were studied on acid-catalyzed reactions. For example, Barth and coworkers studied the effect of $13 \mathrm{wt} . \%$ formic acid in ethanol [17]. At temperatures above $360^{\circ} \mathrm{C}$ the major products were methoxyphenol, catechol, and phenol $[17,24]$. The optimum reaction time was below $200 \mathrm{~min}$. Formic acid/ethanol solutions in the presence of $\mathrm{Pt} / \mathrm{C}$ catalyst allowed for the reduction of all carbonyl groups of the products and provided yields up to $7 \%$ propylguaiacol, $5 \%$ methylguaiacol, and 3\% homovanillyl alcohol [25]. In general, acid-catalyzed depolymerization required harsh reaction conditions, which could affect the cost and economic feasibility of the reaction [13].

\subsection{Oxidative Lignin Depolymerization}

s0070

Oxidative depolymerization to vanillin has p0120 been the main historical industrial process of valorization of vanillin, justified by the high added value of vanillin as a flavor molecule [26].

The cheap and effective oxidizing agent used p0125 is molecular oxygen, bubbled through basic solutions to couple oxidation reactions with alkaline hydrolysis.

Mathias and Rodrigues in 1995 described the p0130 classical state of the art, explaining that $60 \mathrm{~g} / \mathrm{L}$ [03] solution of softwood Kraft lignin, treated at $120-130^{\circ} \mathrm{C}$ for $4-6 \mathrm{~h}$ in the presence of $2 \mathrm{~N} \mathrm{NaOH}$, could yield a maximum $13 \%(\mathrm{w} / \mathrm{w})$ of vanillin [27]. In the same year, the Monsanto process at $160^{\circ} \mathrm{C}$ in $10 \% \mathrm{NaOH}$ solution claimed a yield of vanillin of $19 \%$ when softwood sulfite liquor was oxidized through carefully controlled oxygen pressure [28]. It is interesting to observe that these yields were normalized on the assumed lignin content in the sulfite liquor. When the vanillin yield in the same commercial process was expressed on the basis of the lignosulfonate mass, the yield value was not higher than $7 \%[29,30]$.

The original patent of Monsanto cited the p0135 optional use of $\mathrm{Cu}$ (II) salts as oxidants and catalysts. Copper salts were used when the Monsanto process was bought by Borregaard. and cobalt and cerium salts were also tested [29]. Pacek et al. studied the Borregaard process under highly alkaline conditions, catalyzed by $\mathrm{Cu}^{2+}$ at $120^{\circ} \mathrm{C}, 140^{\circ} \mathrm{C}$, and $160^{\circ} \mathrm{C}$ and pressures up to 10 bars in flow reactors [30]. They were able to determine that nearly $55 \%$ of the vanillin formed was issued from hydrolysis and $45 \%$ from oxidation [6]. Yamamoto et al. found that the use of $\mathrm{Bu}_{4} \mathrm{NOH} \cdot 30 \mathrm{H}_{2} \mathrm{O}$ (tetrabutylammonium hydroxide 30 -hydrate) as reaction medium -instead of the commonly used aqueous $\mathrm{NaOH}$ solution-in aerobic oxidative degradation of lignin improved the yield of aromatic monomers [31]. At $120^{\circ} \mathrm{C}$, total monomer yield of $6.5 \%-22.5 \%$ was obtained with vanillin and vanillic acid as the main products. 
s0075

\section{HETEROGENEOUS CATALYSIS FOR LIGNIN DEPOLYMERIZATION}

p0140 Homogeneous catalysis for the depolymerization of lignin presents several drawbacks, notably in separation of catalyst from the reaction mixture and corrosiveness when strong mineral acid and bases are used [32]. Depolymerization by heterogeneous catalysis offers promising strategies in spite of mass transfer limitations from bulk lignin to catalyst surface [1]. Heterogeneous catalysis means that catalysts and reagents form different physical phases. This type of catalysis is usually favored because it can be carried out over a wide range of operating conditions and offers easy separation and recyclability of the catalyst. The product recovery and purification are significant industrial facets of catalysis, on which the advantages of heterogeneous catalysis are based. As David Parker (ICI) said on April 24, 1988, during the 21st Irvine lectures at the University of St. Andrews in Scotland, "At the molecular level, there is a little to distinguish between homogenous and heterogeneous catalysis, but there are clear distinctions at the industrial level." This chapter discusses the heterogeneous forms of catalysts applied to the fragmentation of lignin via pyrolysis, reduction, and oxidation pathways.

\section{s0080 5.1 Catalytic Pyrolysis}

p0145 Liquefaction by pyrolysis has been developed to convert lignocellulosic biomass to bio-oil. It involves a rapid heating of biomass at high temperatures $\left(450-650^{\circ} \mathrm{C}\right)$ in the absence of oxygen to generate a mixture of noncondensable liquid, gas, and oil mixtures [33]. The main target of biomass pyrolysis is the reduction of the oxygen content of biomass to make it suitable as a fuel component. Lignin, as the biomass component with the lowest $\mathrm{O} / \mathrm{C}$ ratio, has been extensively studied as a bio-oil precursor. Indeed, the activation energy of lignin pyrolysis is lower than the activation energy of cellulose pyrolysis [34].

The requirement for high temperatures of the p0150 pyrolysis processes is energy intensive and the final product is a mixture of a large number of components, mainly substituted aromatics. It is considered that the product distribution is the result of a number of reactions where nonvolatile compounds are broken down into heavy volatile compounds at first, and finally cracked into volatile alkyl aromatics and ultimately to coke and gas [33].

The addition of a catalyst to the pyrolysis p0155 reactor introduces some selectivity and directs the distribution of the product stream toward higher-value desired products. The proportion of each pyrolysis product is dependent on the process variables, particularly temperature and heating rate [34]. At lower temperatures the first bonds cleaved are hydroxyl and ether groups attached to alpha or beta carbons to form condensable volatile products and water. Large fractions of methoxyphenols, such as substituted syringol and guaiacol, are present in the condensable volatile products as the methoxyl groups show more resistance than the ether linkages against thermal degradation. $\mathrm{C}-\mathrm{C}$ bond is the strongest bond in many transformations, its breaking only occurring at very high temperatures [35].

Several kinds of catalysts have been tested for p0160 lignin pyrolysis. Zhan et al. studied the product distribution obtained from lignin at $400^{\circ} \mathrm{C}$, $500^{\circ} \mathrm{C}$, and $600^{\circ} \mathrm{C}$ on several catalysts with different pore structures and acidity-HZSM-5, $\mathrm{MCM}-41, \mathrm{TiO}_{2}, \mathrm{ZrO}_{2}$, and $\mathrm{Mg}(\mathrm{Al}) \mathrm{O}$ [36]. It was concluded that HZSM-5 was the best catalyst for fast pyrolysis whereas the basic catalysts trigger reduction of the liquid, leading to oligomers and coke formation. Ohra-aho and Linnekoski studied the activity of HZSM-5, zeolite $\mathrm{Y}$, and $\mathrm{Pd} / \mathrm{C}$ on Kraft lignin and pine wood 
lignin at $600^{\circ} \mathrm{C}$. The catalyst with the larger influence on product distribution was the zeolite $Y$, which increased the extent of demethylation and demethoxylation of the monoaromatic products [37]. The yield of liquid and the selectivity of products can be monitored by tuning acidity and pore size of zeolites. Ma et al. compared the activity of several zeolites with micropore size from 0.5 to $0.7 \mathrm{~nm}$, and the $\mathrm{Si} / \mathrm{Al}$ ratio from 7 to all silica [38]. Zeolite US-Y, the catalyst with the largest pores and the highest density of acid sites, allowed for an increase of the yield of liquid to $75 \%$ from $40 \%$ without a catalyst. Zeolite H-ZSM5 with smaller pores and a smaller number of stronger acid sites was able to increase the selectivity of phenol alkoxy species. The small size of pores is expected to prevent repolymerization and coke formation reactions.

p0165 Studies on model molecules have contributed to a better understanding of the mechanisms of lignin pyrolysis. For instance, Zhang et al. have recently investigated the catalytic pyrolysis products of guaiacol over ZSM- 5 between $400^{\circ}$ $\mathrm{C}$ and $650^{\circ} \mathrm{C}$, showing that the mechanisms of pyrolysis are similar to the dehydration, decarbonylation, and hydrogen transfer pattern of the geological formation of coal and hydrocarbons from lignocellulosic biomass $[39,40]$.

\section{s0085 5.2 Reductive Transformations}

p0170 The idea of reductive depolymerization of lignin began in the late 1930s when the insoluble biomass isolated from tree sawdust was hydrogenated. The selective catalytic reduction of lignin has attained great attraction for the improvement of bio-oil over the past few years. For lignin reductions, typical reactions involve the removal of the extensive functionalities of the lignin subunits to form less substituted monomeric compounds, such as phenols, benzene, toluene, or xylene (BTX). These simple aromatic compounds can then be hydrogenated to alkanes for fuel applications or used as platform chemicals for the synthesis of bulk and fine chemicals using technology already developed by the petrochemical industry. The biomass or lignin model molecules are subjected to hydrogenating conditions for the production of high yield phenols and aromatics. Oxygen is generally removed in the form of $\mathrm{H}_{2} \mathrm{O}$ and $\mathrm{CO} / \mathrm{CO}_{2}$ by means of different catalytic processes such as hydrogenation, $\mathrm{C}-\mathrm{O}$ bond hydrogenolysis, dehydration, decarboxylation, and decarbonylation [1]. Bifunctional catalysts having both acid and noble metal can give interesting results where they can simultaneously break ether bonds and deoxygenate the resulting monomers in the presence of $\mathrm{H}$-donor solvent or $\mathrm{H}_{2}$.

In 1938, Harris et al. studied the catalytic p0175 hydrogenation of hardwood lignin at $260^{\circ} \mathrm{C}$ for $18 \mathrm{~h}$ in the presence of a copper-chromium oxide catalyst and successfully achieved $70 \%$ conversion [41].

Pepper et al. extended comparative studies p0180 on the effectiveness of different metal catalysts (Raney $\mathrm{Ni}, \mathrm{Pd} / \mathrm{C}, \mathrm{Rh} / \mathrm{C}, \mathrm{Rh} / \mathrm{Al}_{2} \mathrm{O}_{3}, \mathrm{Ru} / \mathrm{C}$, $\mathrm{Ru} / \mathrm{Al}_{2} \mathrm{O}_{3}$ ) for the hydrogenolysis of spruce wood lignin in dioxane/water at $195^{\circ} \mathrm{C}$ under 3.3 $\mathrm{MPa} \mathrm{H}_{2}$ pressure [42]. The best results were obtained on $\mathrm{Rh} / \mathrm{C}$, with a yield of identified monomers of $33 \%$, the main products being 4-propylguaiacol and dihydroconiferyl alcohol [43]. The distribution of products was greatly influenced by catalyst loading and $\mathrm{pH}$ variations resulting in over-hydrogenated or degraded products.

In previous years, many types of metal cata- p0185 lysts have been tested for hydrogenation of model molecules, commercial lignin or ligninissued bio-oil (see Table 13.1). Metal catalysts are very effective in the improvement of the fuel properties of bio-oil, by decreasing its $\mathrm{O} / \mathrm{C}$ ratio. Hydrodeoxygenation of substituted guaiacols and syringols, among the main components of bio-oil, was achieved on a variety of metal catalysts at $250-300^{\circ} \mathrm{C}$ under $40-50$ bar $\mathrm{H}_{2}$ with high yields of cycloalkanes, provided an 
t0010 TABLE 13.1 Some Recent Literature on the Heterogeneous Catalysis of Hydrogenation of Lignin and Model Molecules

\begin{tabular}{|c|c|c|c|c|c|}
\hline Catalyst & Solvent & $\begin{array}{l}\text { Experimental } \\
\text { Conditions }\end{array}$ & Substrate & Major Products & Ref. \\
\hline $\mathrm{Pd} / \mathrm{C}, \mathrm{H}_{3} \mathrm{PO}_{4}$ & $\mathrm{H}_{2} \mathrm{O}$ & $250^{\circ} \mathrm{C}, 50$ bars $\mathrm{H}_{2}$ & Phenolic monomers & $79 \%$ cycloalkanes & [44] \\
\hline $\mathrm{Ni} / \mathrm{SiO}_{2}-\mathrm{ZrO}_{2}$ & Dodecane & $300^{\circ} \mathrm{C}, 50$ bars $\mathrm{H}_{2}$ & Guaiacol & 97\% cyclohexane & [45] \\
\hline Raney $\mathrm{Ni}+$ Nafion $/ \mathrm{SiO}_{2}$ & $\mathrm{H}_{2} \mathrm{O}$ & $300^{\circ} \mathrm{C}, 40$ bars $\mathrm{H}_{2}$ & 4-Propylguaiacol & $74 \%$ alkylcyclohexane & [46] \\
\hline $\mathrm{RhPt} / \mathrm{ZrO}_{2}$ & Tetradecane & $400^{\circ} \mathrm{C}, 50$ bars $\mathrm{H}_{2}$ & Guaiacol & $43 \%$ cyxlohexane & [47] \\
\hline Rh/Ru nanoparticles & {$[\mathrm{bmim}][\mathrm{TF} 2 \mathrm{~N}]$} & $130^{\circ} \mathrm{C}, 40$ bars $\mathrm{H}_{2}$ & 4-Ethylphenol & 99\% ethylcyclohexane & [48] \\
\hline $\mathrm{Ru} / \mathrm{Nb}_{2} \mathrm{O}_{5}$ & $\mathrm{H}_{2} \mathrm{O}$ & $250^{\circ} \mathrm{C}, 7$ bars $\mathrm{H}_{2}$ & Birch lignin & $\begin{array}{l}21 \% \text { arenes, } 8 \% \\
\text { cycloalkanes }\end{array}$ & [49] \\
\hline $\mathrm{Ru} / \mathrm{C}$ & THF & $250^{\circ} \mathrm{C}, 40$ bars $\mathrm{H}_{2}$ & $\begin{array}{l}\text { Formaldehyde- } \\
\text { treated beech lignin }\end{array}$ & $77 \%$ phenolic monomers & [50] \\
\hline $\mathrm{Ni} / \mathrm{C}$ & THFA, dioxane & $220^{\circ} \mathrm{C}, 20$ bars $\mathrm{H}_{2}$ & Beech lignin & $14 \%$ phenolic monomers & [51] \\
\hline Ni7Au3, $\mathrm{NaOH}$ & $\mathrm{H}_{2} \mathrm{O}$ & $160^{\circ} \mathrm{C}, 10$ bars $\mathrm{H}_{2}$ & Birch lignin & $11 \%$ phenolic monomers & [52] \\
\hline $\mathrm{Zn} / \mathrm{Pd} / \mathrm{C}$ & Methanol & $150^{\circ} \mathrm{C}, 20$ bars $\mathrm{H}_{2}$ & Vanillin & $81 \%$ creosol & [53] \\
\hline $\mathrm{Ni} / \mathrm{TiN}$ & Ethanol & $150^{\circ} \mathrm{C}, 12$ bars $\mathrm{H}_{2}$ & Diphenyl ether & $\begin{array}{l}49 \% \text { cyclohexanol, } 46 \% \\
\text { benzene }\end{array}$ & [54] \\
\hline $\mathrm{Ni} / \mathrm{SiO}_{2}$ & Decalin & $130^{\circ} \mathrm{C}, 30$ bars $\mathrm{H}_{2}$ & Dihydrobenzofuran & 95\% 2-ethylphenol & [55] \\
\hline $\mathrm{Pt} / \mathrm{SiO}_{2}$ & Gas phase & $400^{\circ} \mathrm{C}$, flowing $\mathrm{H}_{2}$ & Anisole & $42 \%$ phenol, $33 \%$ cresols & [56] \\
\hline $\mathrm{Pt} / \mathrm{HBeta}$ & Gas phase & $400^{\circ} \mathrm{C}$, flowing $\mathrm{H}_{2}$ & Anisole & $52 \%$ benzene, $28 \%$ toluene & [56] \\
\hline $\mathrm{Pd} / \mathrm{C}$ & Dioxar & $200^{\circ} \mathrm{C}, 1$ bars $\mathrm{H}_{2}$ & Miscanthus lignin & $15 \%$ phenolic monomers & [57] \\
\hline Raney Ni-H-USY & Aqueous methanol & $270^{\circ} \mathrm{C}, \mathrm{N}_{2}$ & Bamboo lignin & $28 \%$ phenolic monomers & [58] \\
\hline $\mathrm{Ni} / \mathrm{C}$ & Methanol & $200^{\circ} \mathrm{C}, \mathrm{Ar}$ & Birch lignin & $49 \%$ phenolic monomers & [59] \\
\hline $\mathrm{CoMo} / \mathrm{Al}_{2} \mathrm{O}_{3}$ & Hexadecane & $300^{\circ} \mathrm{C}, 69$ bars $\mathrm{H}_{2}$ & 4-Methylcathecol & $\begin{array}{l}25 \% \text { methylcyclohexane, } \\
20 \% \text { cresol }\end{array}$ & [60] \\
\hline $\mathrm{Cu}-\mathrm{Mg}-\mathrm{Al}$ mixed oxides & Methanol & $180^{\circ} \mathrm{C}, 40$ bars $\mathrm{H}_{2}$ & Organosolv lignin & $63 \%$ phenolic monomers & [61] \\
\hline $\mathrm{MoOx} / \mathrm{CNT}$ & Methanol & $260^{\circ} \mathrm{C}, 30$ bars $\mathrm{H}_{2}$ & Birch lignin & $47 \%$ phenolic monomers & [62] \\
\hline CoMo, NiMo & Tetradecane & $400^{\circ} \mathrm{C}, 50$ bars $\mathrm{H}_{2}$ & Guaiacol & $46 \%$ phenolic monomers & [47] \\
\hline $\mathrm{Mo}_{2} \mathrm{~N}$ & Decalin & $300^{\circ} \mathrm{C}, 50$ bars $\mathrm{H}_{2}$ & Guaiacol & $47 \%$ phenol & [63] \\
\hline $\mathrm{FeS}_{2} / \mathrm{C}$ & Cyclohexane & $300^{\circ} \mathrm{C}, 100$ bars $\mathrm{H}_{2}$ & Dibenzyl ether & $98 \%$ toluene & [64] \\
\hline $\mathrm{MoO}_{3}$ & Gas phase & $320^{\circ} \mathrm{C}$, flowing $\mathrm{H}_{2}$ & Guaiacol & $31 \%$ phenol & [65] \\
\hline $\mathrm{MoO}_{3}$ & Gas phase & $320^{\circ} \mathrm{C}$, flowing $\mathrm{H}_{2}$ & Anisole & $44 \%$ benzene & [65] \\
\hline $\begin{array}{l}\mathrm{Ni}_{2} \mathrm{P} / \mathrm{SiO}_{2} \text { or } \\
\mathrm{Co}_{2} \mathrm{P} / \mathrm{SiO}_{2}\end{array}$ & Gas phase & $\begin{array}{l}300^{\circ} \mathrm{C} \text {, flowing } \\
20 \% \mathrm{H}_{2} \text { in } \mathrm{N}_{2}\end{array}$ & Guaiacol & $48 \%$ benzene & [66] \\
\hline $\mathrm{WP} / \mathrm{SiO}_{2}$ & Gas phase & $\begin{array}{l}300^{\circ} \mathrm{C} \text {, flowing } \\
20 \% \mathrm{H}_{2} \text { in } \mathrm{N}_{2}\end{array}$ & Guaiacol & $60 \%$ phenol & [66] \\
\hline
\end{tabular}


12

13. HETEROGENEOUS GATALYSIS, acid function was also present [44-46]. The nature of the metal catalysts used spanned from noble metal palladium to Raney nickel and the acid function could be provided by the addition of an inorganic acid, such as $\mathrm{H}_{3} \mathrm{PO}_{4}$ [44], or by a heterogeneous co-catalyst, such as silicazirconia or Nafion $[45,46]$. At such high temperatures, water has proven to be a good solvent for the reaction, allowing easy separation of the less polar hydrocarbon products at the end of the process $[44,46,49]$. The use of $\mathrm{Rh} / \mathrm{Ru}$ nanoparticles and a Brønsted-acid ionic liquid ([bmim][TF2N], 1-butyl-3-methylimidazolium bis(trifluoromethanesulfonyl)imide) as the solvent allowed for still higher yields of cycloalkanes at a much lower temperature of $130^{\circ} \mathrm{C}$ [48], while a lower hydrogen pressure of 7 bar allowed only partial depolymerization and hydrogenation of lignin, giving a low yield of arenes and cyclohexanes [49].

p0190 In the absence of an acid function, metal catalysts allowed effective depolymerization of lignin at $250^{\circ} \mathrm{C}$ under 40 bar $\mathrm{H}_{2}$ but the product was mainly a phenolic bio-oil with no significant hydrogenation of the aromatic rings [50]. Metal catalysts as different as $\mathrm{Ru}, \mathrm{Ni}, \mathrm{Zn}, \mathrm{Pd}, \mathrm{Ni}_{7} \mathrm{Au}_{3}$ have been used with yields of phenolic monomers mainly depending on temperature and $\mathrm{H}_{2}$ pressure [50-53]. Lin et al. studied the mechanism of hydrodeoxygenation of guaiacol, using mono and bimetallic Rh-based catalysts on zirconia and showed that RhPt significantly accelerated the hydrogenation to cycloalkanes by comparison to plain $\mathrm{Rh}$ or $\mathrm{RhPd}$ [47]. Studies on model molecules showed that ether bonds were easily cleaved also in mild hydrogenation conditions $[54,55]$.

p0195 The difference between simple metal catalysts and bifunctional metal-acid catalysts was highlighted by Zhu et al. in a mechanistic study of the hydrogenation of anisole (methoxybenzene) over a bifunctional metal-zeolite catalyst $\mathrm{Pt} / \mathrm{HBeta}$ or a monofunctional catalyst $\mathrm{Pt} / \mathrm{SiO}_{2}$ [56]. Anisole fed in gas phase at $400^{\circ} \mathrm{C}$ in flowing
$\mathrm{H}_{2}$ at atmospheric pressure was converted to phenolic monomers by demethylation and transalkylation on the metal catalyst and was hydrogenated to BTX (benzene, toluene, xylene) on the bifunctional catalyst.

Molecular hydrogen was not the only possible p0200 agent of hydrodeoxygenation of lignin. Internal hydrogen transfer from alcohol groups has been suggested by Hartwig and co-workers to be active in breaking ether bonds of lignin [57]. They found that $\mathrm{H}_{2}$ pressure of $1 \mathrm{~atm}$ was used to reduce the weak amount of olefinic bonds present in the miscanthus lignin used. Hydrogen transfer from a hydrogen-donor solvent has been shown to be effective in the hydrodeoxygenation of lignin, $49 \%$ yield of phenolic monomers having been attained by treatment of birch lignin in methanol on a Ni/C catalyst at $200^{\circ} \mathrm{C}$ in an inert atmosphere $[58,59]$.

Nonmetal catalysts were also tested in lignin p0205 hydrogenation, looking for a parallel with the highly stable classical sulfided CoMo and NiMo hydrotreatment catalysts of oil refineries. In a seminal study, Petrocelli and Klein investigated the hydrodeoxygenation of several model compounds over a sulfided $\mathrm{CoOMoO}_{3} / \gamma-\mathrm{Al}_{2} \mathrm{O}_{3}$ commercial catalyst at $300^{\circ} \mathrm{C}$ and $69 \mathrm{bars}$ of hydrogen pressure [60]. Compounds with aromatic methoxyl groups (4-methylguaiaco1, eugenol, vanillin) underwent primary demethylation as their major reaction. Hydroxyl groups were removed readily at temperatures well below those required for thermal dehydroxylation. Catalytic cleavage of the inter-aromatic unit linkages of $o$-hydroxydiphenylmethane and phenyl ether was facile, while $o, o^{\prime}$-biphenol was converted to single-ring products through dibenzofuran and 2-phenylphenol intermediates. Previously, yields of phenolic monomers as high as $47 \%-63 \%$ were obtained by lignin depolymerization at $180-260^{\circ} \mathrm{C}$ under $30-50$ bar $\mathrm{H}_{2}$ on catalysts as different as $\mathrm{Cu}$-bearing basic mixed oxides issued from hydrotalcite decomposition or on molybdenum oxides on carbon nanotubes $[61,62]$. Molybdenum oxides and nitrides, as well 
as sulfides and phosphides of different metals, were tested in mechanistic studies of hydrodeoxygenation of model molecules at temperatures as high as $400^{\circ} \mathrm{C}$ and under $\mathrm{H}_{2}$ pressure up to 100 bars or in a flowing hydrogen atmosphere [47,63-66]. The main results of these studies were the suggestion of a scale of reactivity of the functional group of phenolic molecules, with ether bonds being more easily hydrogenated than methoxy groups, phenolic $\mathrm{OH}$ being the more resistant to hydrodeoxygenation. The interest of flow processes for the depolymerization of lignin is evident, albeit the results on model molecules in the gas phase at high temperatures are surely difficult to transpose to the reactivity of lignin of higher molecular weight.

\section{s0090 5.3 Oxidative Transformations}

p0210 Oxidative treatments of lignin are aimed to the production of high added-value aromatics, especially aromatic aldehyde flavors. The increase of the $\mathrm{O} / \mathrm{C}$ ratio in oxidative treatments render them inappropriate for the production of fuels but justifies some interest in total oxidation of lignin-containing paper mill wastes or selective oxidation of lignin-derived alcohols to aldehydes [12,67-69]. In this chapter, we will only examine applications of heterogeneous catalysis to selective oxidative fractionation of lignin or [Q4] model oligomers (Table 13.2).

p0215 The formation of aromatic aldehydes by oxidative cleavage of model molecules containing $\beta-\mathrm{O}-4$ bonds was studied on supported homogeneous catalysts using hydrogen peroxide as the oxidant. Crestini et al. used methyltrioxorhenium immobilized on poly(4-vinyl pyridine) or polystyrene at room temperature in acetic acid whereas Badamali et al. used Co(salen) complexes in SBA-15 mesoporous silica in acetonitrile with microwave heating, obtaining $21 \%-28 \%$ yields of guaiacol [70,71]. Mottweiler et al. inspected $\mathrm{Cu}-\mathrm{V}$ hydrotalcites for catalytic activity in the cleavage of the lignin model compound erythro- 1-(3,4-dimethoxyphenyl)-2-(2-methoxyphenoxy)1,3-propanediol with molecular oxygen as the oxidant [72]. High yield of veratrylaldehyde was observed at $130^{\circ} \mathrm{C}$ but pyridine had to be used as a solvent of the reaction.

Nitrogen-containing graphene materials were p0220 also tested for the oxidative cleavage of $\beta-\mathrm{O}-4$ bonds by using tert-butyl hydroperoxide as the oxidant [73]. Also at the mild temperature of $120^{\circ} \mathrm{C}$, overoxidation to benzylic acid was observed. Deng et al. tested several nonnoble metal oxides as catalysts and reported that cerium oxide can efficiently catalyze the one-pot oxidative conversion of 2-phenoxy-1-phenylethanol in methanol under 10 bars of molecular oxygen [74]. The presence of a noble metal in $\mathrm{CeO}_{2-}$ supported palladium nanoparticles $\left(\mathrm{Pd} / \mathrm{CeO}_{2}\right)$ allowed them to be reduced by a factor of 10 , the oxygen pressure needed for the reaction. With both catalytic systems, overoxidation of tolualdehyde to methyl benzoate was observed. The same $\mathrm{Pd} / \mathrm{CeO}_{2}$ catalyst was used in the same reaction conditions-not on a model system but on organosolv lignin. On such a more demanding substrate, high yields of syringaldehyde and vanillin were obtained [74].

Indeed, several heterogeneous catalysts have p0225 been successfully used in oxidative depolymerization of several kinds of lignin in conditions similar to the ones of the Monsanto-Borregaard process for the synthesis of vanillin. Sales et al. employed $\mathrm{Pd} / \gamma-\mathrm{Al}_{2} \mathrm{O}_{3}$ catalysts for the oxidative conversion of alkaline lignin extracted from sugar cane bagasse in both batch slurry and continuous fluidized-bed reactors [75]. Good yields of syringaldehyde and vanillin were obtained in $2 \mathrm{M}$ aqueous $\mathrm{NaOH}$ solution at $120-140^{\circ} \mathrm{C}$. The use of the perovskite-type mixed oxides $\mathrm{LaM}_{1-x} \mathrm{Cu}_{x} \mathrm{O}_{3}(\mathrm{M}=\mathrm{Co}$ or $\mathrm{Fe})$ has been proposed for the wet aerobic oxidation of cornstalk enzymatic lignin in $2 \mathrm{M} \mathrm{NaOH}$ under 5 bars $\mathrm{O}_{2}$. Yields of aromatic aldehydes comparable to the Monsanto process were reported and the catalysts were stable after a series of successive 
B978-0-444-64127-4.00013-6, 00013

14

13. HETEROGENEQUS GATALYSIS,

TABLE 13.2 Some Literature on the Oxidation of Lignin and Lignin Model Oligomers by Heterogeneous Catalysis

\begin{tabular}{|c|c|c|c|c|c|c|}
\hline Catalyst & Oxidant & Solvent & $\begin{array}{l}\text { Experimental } \\
\text { Conditions }\end{array}$ & Substrate & Major Products Yield & Ref. \\
\hline $\begin{array}{l}\mathrm{MeRhO}_{3} / \text { polyvinyl } \\
\text { pyridine }\end{array}$ & $\mathrm{H}_{2} \mathrm{O}_{2}$ & $\mathrm{CH}_{3} \mathrm{COOH}$ & Room $\mathrm{T}$ & $\begin{array}{l}\beta-\mathrm{O}-4 \text { phenolic } \\
\text { dimer }\end{array}$ & $28 \%$ guaiacol & [70] \\
\hline Co-salen/SBA-15 & $\mathrm{H}_{2} \mathrm{O}_{2}$ & acetonitrile & $\begin{array}{l}150^{\circ} \mathrm{C} \\
\text { microwaves }\end{array}$ & $\begin{array}{l}\beta-\mathrm{O}-4 \text { phenolic } \\
\text { dimer }\end{array}$ & $21 \%$ guaiacol & [71] \\
\hline $\mathrm{Cu}, \mathrm{V}$-hydrotalcite & $\mathrm{O}_{2} 6$ bars & Pyridine & $135^{\circ} \mathrm{C}$ & $\begin{array}{l}\beta-O-4 \text { phenolic } \\
\text { dimer }\end{array}$ & $38 \%$ veratrylaldehyde & [72] \\
\hline Graphene nitride & $\begin{array}{l}\text { tert-Butyl } \\
\text { hydroperoxide }\end{array}$ & $\mathrm{H}_{2} \mathrm{O}$ & $120^{\circ} \mathrm{C}$ & $\begin{array}{l}\beta \text {-O-4 phenolic } \\
\text { dimer }\end{array}$ & $45 \%$ benzylic acid & [73] \\
\hline $\mathrm{CeO}_{2}$ & $\mathrm{O}_{2} 10 \mathrm{bar}$ & Methanol & & $\begin{array}{l}\beta-\mathrm{O}-4 \text { phenolic } \\
\text { dimer }\end{array}$ & $\begin{array}{l}42 \% \text { phenol, } 40 \% \\
\text { methylbenzoate }\end{array}$ & [74] \\
\hline $\mathrm{Pd} / \mathrm{CeO}_{2}$ & $\mathrm{O}_{2} 1$ bar & Methanol & & $\begin{array}{l}\beta \text {-O-4 phenolic } \\
\text { dimer }\end{array}$ & $\begin{array}{l}41 \% \text { phenol, } 20 \% \\
\text { methylbenzoate }\end{array}$ & [74] \\
\hline $\mathrm{Pd} / \mathrm{CeO}_{2}$ & $\mathrm{O}_{2} 1$ bar & Methanol & $1050 \mathrm{C}$ & $\begin{array}{l}\text { Organosolv } \\
\text { lignin }\end{array}$ & $\begin{array}{l}5 \% \text { vanillin, } 2 \% \\
\text { hydroxybenzaldehyde }\end{array}$ & [52] \\
\hline $\mathrm{Pd} / \mathrm{Al}_{2} \mathrm{O}_{3}$ & $\mathrm{O}_{2} 5$ bars & $\begin{array}{l}\text { Aqueo } \\
\mathrm{NaOH}\end{array}$ & $\begin{array}{l}140^{\circ} \mathrm{C} \text {, flow } \\
\text { reactor }\end{array}$ & $\begin{array}{l}\text { Alkaline bagasse } \\
\text { lignin }\end{array}$ & $\begin{array}{l}7 \% \\
\text { hydroxybenzaldehyde, } \\
5 \% \text { vanillin }\end{array}$ & [75] \\
\hline $\begin{array}{l}\mathrm{La}(\mathrm{Co}, \mathrm{Cu}) \mathrm{O}_{3} \\
\text { perovskite }\end{array}$ & $\mathrm{O}_{2} 5$ bars & $\begin{array}{l}\text { Aqueous 2M } \\
\mathrm{NaOH}\end{array}$ & $120^{\circ} \mathrm{C}$ & $\begin{array}{l}\text { Steam-exploded } \\
\text { cornstalk lignin }\end{array}$ & $\begin{array}{l}12 \% \text { syringaldehyde, } \\
5 \% \text { vanillin }\end{array}$ & [76] \\
\hline $\begin{array}{l}\mathrm{La}(\mathrm{Fe}, \mathrm{Cu}) \mathrm{O}_{3} \\
\text { perovskite }\end{array}$ & $\mathrm{O}_{2} 5$ bars & Aqueous 2 & $120^{\circ} \mathrm{C}$ & $\begin{array}{l}\text { Steam-exploded } \\
\text { cornstalk lignin }\end{array}$ & $\begin{array}{l}12 \% \text { syringaldehyde, } \\
4 \% \text { vanillin }\end{array}$ & [77] \\
\hline La-SBA-15 & $\mathrm{H}_{2} \mathrm{O}_{2}$ & $\begin{array}{l}\text { Aqueous 2M } \\
\mathrm{NaOH}\end{array}$ & microwaves & $\begin{array}{l}\text { Organosolv } \\
\text { beech lignin }\end{array}$ & $\begin{array}{l}15 \% \text { syringaldehyde, } \\
9 \% \text { vanillin }\end{array}$ & [78] \\
\hline
\end{tabular}

recycling [76,77]. The best yields in syringaldehyde and lignin from organosolv lignin were reported in a microwave-heated $2 \mathrm{M} \mathrm{NaOH}$ solution by using hydrogen peroxide as the oxidant and La-SBA-15 as the catalyst [78].

p0230 Pineda and Lee reported that oxidative protocols could sometime result in undesirable products because of free radicals-driven recondensation [32]. More complex multistep reaction pathways have been proposed in order to use milder conditions for each step of the process. Samec and coworkers investigated a mild and chemoselective oxidation of $\alpha$-alcohols $\beta-\mathrm{O}-4$ glycerolaryl ethers at $80^{\circ} \mathrm{C}$ on $\mathrm{Pd} / \mathrm{C}$ catalysts $[79,80]$. In this reaction, the benzylic alcohol groups were selectively oxydehydrogenated to the corresponding ketones attaining 60\%-93\% of yield. Successive Pd-catalyzed $\beta-\mathrm{O}-4$ bond cleavage of the obtained 2-aryloxy-1-arylethanols by hydrogen transfer from formic acid reached $92 \%-98 \%$ yields of 3,4-dimethoxypropiophenone proposed as a platform molecule.

\section{ECONOMICAL ASPECTS OF LIGNIN VALORIZATION}

Virtually all lignin presently available is a p0235 coproduct of the pulp and paper industry. However, the development of second-generation 
biorefineries is providing new industrial sources of isolated lignin. The concept of lignocellulose biorefinery is born with the perceived need of second-generation biofuels to ensure sustainability while avoiding direct competition with food resources [81,82]. The installation of biorefinery plants based on new technologies of biomass fractionation opens the way to the integration of optimized lignin recovery in the plant design $[83,84]$. The introduction of more advanced plants is one of the aspects of the current trend of shifting the design of biorefineries away from the production of biofuels and toward the production of higher valueadded chemicals able to replace present fossilissued products $[85,86]$.

p0240 A significant hurdle in the development of profitable biorefineries is the adaptation to variability and seasonality of the biomass supply. Wood-issued lignin from the different processes of the pulp and paper industry enjoys a constant supply and a stable price throughout the year, while other lignin sources, notably from cornstalks and wheat or rice straw, present a significant seasonal variability. In any case, the status of lignin as a coproduct of the profitable cellulose industry provides it with a reasonable entry price, at the basis of its possible competition with oil-derived raw materials for the production of chemicals (see Table 13.3).
Clearly lignin, with a higher heating value of p0245 $21 \mathrm{MJ} \mathrm{kg}^{-1}$, is a very poor fuel when compared with liquid hydrocarbons with a heating value of $45 \mathrm{MJ} \mathrm{kg}^{-1}$. The same oxygen content which lowers the fuel performance of lignin necessary decreases the atomic yield of the production of any hydrodeoxygenation products. Albeit lignin, with a lower oxygen content than cellulose, can improve the yields of bio-oil production from biomass. It seems clear that production of valuable chemicals from lignin has to be based on the retention of useful functional groups already present in the raw material.

The retention of the aromatic rings by lignin p0250 hydrogenation to BTX has been developed at the pilot scale, despite the development of the process be hampered by the formation of chars which decreases the yield and poison the catalyst, as well as by the high selectivity to metaxylene, the less valuable fraction of BTX [92]. The heavy burden of the cost of hydrogen strongly suggests that lignin be used for the production of oxygen-rich products rather than for fuels or base hydrocarbon chemicals [93].

Indeed, the exploitation of substituted pheno- p0255 lics present in native lignin is at the basis of the production of high added-value flavors like vanillin and derivatives, a traditional staple of biorefinery [94]. Other functionalized phenolics can provide valuable market outlets but the

t0020 TABLE 13.3 Market Values of Medium-Grade Lignins Compared With Fossil Oil, Significant Reagents, and Potential Products [87-91]

\begin{tabular}{lllc}
\hline Lignins, Competitor and Reagents & $\$$ /ton & Products & \$/ton \\
\hline Kraft lignin & $260-500$ & Vanillin & $15,000-40,000$ \\
Lignosulfonates & $180-500$ & 4 -Hydroxybenzaldehyde & $9500-11,100$ \\
Soda lignin & $200-300$ & Phenol & $1400-1620$ \\
Organosolv lignin & $280-520$ & Benzene & $830-1280$ \\
Brent crude oil & 490 & Toluene & $690-980$ \\
Methanol & $460-490$ & Xylenes & $690-1000$ \\
Hydrogen & $\sim 3900$ & & \\
\hline
\end{tabular}


formation of many products, each with relatively low yields, made separation issues critical for the viability of biorefinery processes $[95,96]$.

p0260 It is clear that better economic returns require the development of technologies integrating easier fractionation of lignocellulosic biomass and more selective depolymerization. A fuller exploitation of the lignin potential as a source of aromatics remains a worthy technological challenge.

\section{References}

[1] C. Xu, R.A.D. Arancon, J. Labidi, R. Luque, Lignin depolymerization strategies: towards valuable chemicals and fuels, Chem. Soc. Rev. 43 (2014) 7485-7500.

[2] J.C. Serrano-Ruiz, R. Luque, A. Sepulveda-Escribano, Transformations of biomass-derived platform molecules: from high added-value chemicals to fuels via aqueousphase processing, Chem. Soc. Rev. 40 (2011) 5266-5281.

[3] C. Li, X. Zhao, A. Wang, G.W. Huber, T. Zhang, Catalytic transformation of lignin for the production of chemicals and fuels, Chem. Rev. 115 (2015) 11559-11624.

[4] C. Cheng, J. Wang, D. Shen, J. Xue, S. Guan, S. Gu, K. H. Luo, Catalytic oxidation of lignin in solvent systems for production of renewable chemicals: a review, Polymers 9 (2017) 240.

[5] F.G. Calvo-Flores, J.A. Dobado, J. Isac-García, F.J. Martín-Martínez (Eds.), Lignin and Lignans as Renewable Raw Materials: Chemistry, Technology and Applications, John Wiley \& Sons, New York, 2015, pp. 9-48.

[6] W. Boerjan, J. Ralph, M. Baucher, Lignin biosynthesis, Annu. Rev. Plant Biol. 54 (2003) 519-546.

[7] J. Zakzeski, P.C.A. Bruijnincx, A.L. Jongerius, B. M. Weckhuysen, The catalytic valorization of lignin for the production of renewable chemicals, Chem. Rev. 110 (2010) 3552-3599.

[8] S. Dutta, K.C.W. Wu, B. Saha, Emerging strategies for breaking the 3D amorphous network of lignin, Catal. Sci. Technol. 4 (2014) 3785-3799.

[9] R.J.A. Gosselink, M.H.B. Snijder, A. Kranenbarg, E.R. P. Keijsers, E. de Jong, L.L. Stigsson, Characterisation and application of NovaFiber lignin, Ind. Crops Prod. 20 (2004) 191-203.

[10] Z. Sun, B. Fridrich, A. de Santi, S. Elangovan, K. Barta, Bright side of lignin depolymerization: toward new platform chemicals, Chem. Rev. 118 (2018) 614-678.

[11] F.S. Chakar, A.J. Ragauskas, Review of current and future softwood kraft lignin process chemistry, Ind. Crop. Prod. 20 (2004) 131-141.
[12] J. Zakzeski, A. Debczak, P.C.A. Bruijnincx, B. M. Weckhuysen, Catalytic oxidation of aromatic oxygenates by the heterogeneous catalyst Co-ZIF-9, Appl. Catal. A 394 (2011) 79-85.

[13] H. Wang, M. Tucker, Y. Ji, Recent development in chemical depolymerization of lignin: a review, J. Appl. Chem. 2013 (2013).

[14] M.P. Pandey, C.S. Kim, Lignin depolymerization and conversion: a review of thermochemical methods, Chem. Eng. Technol. 34 (2011) 29-41.

[15] D. Ferdous, A.K. Dalai, S.K. Bej, R.W. Thring, Pyrolysis of lignins: experimental and kinetics studies, Energy Fuel 16 (2002) 1405-1412.

[16] N.S. Reading, K.D. Welch, S.D. Aust, Free radical reactions of wood-degrading fungi, in: B. Goodell, D. D. Nicholas, T.P. Schultz (Eds.), Wood Deterioration and Preservation, 2003, American Chemical Society Symposium Series, vol. 845, American Chemical Society, 2003, pp. 16-31.

[17] J.R. Gasson, D. Forchheim, T. Sutter, U. Hornung, A. Kruse, T. Barth, Modeling the lignin degradation kinetics in an ethanol/formic acid solvolysis approach. Part 1. Kinetic model development, Ind. Eng. Chem. Res. 51 (2012) 10595-10606.

[18] Z.S. Yuan, S.N. Cheng, M. Leitch, C.B. Xu, Hydrolytic degradation of alkaline lignin in hot-compressed water and ethanol, Bioresour. Technol. 101 (2010) 9308-9313.

[19] N. Mahmood, Z. Yuan, J. Schmidt, C.C. Xu, Production of polyols via direct hydrolysis of kraft lignin: effect of process parameters, Bioresour. Technol. 139 (2013) 13-20.

[20] R. Beauchet, F. Monteil-Rivera, J.M. Lavoie, Conversion of lignin to aromatic-based chemicals (L-chems) and biofuels (L-fuels), Bioresour. Technol. 121 (2012) 328-334.

[21] V. Roberts, V. Stein, T. Reiner, A. Lemonidou, X. Li, J. A. Lercher, Towards quantitative catalytic lignin depolymerization, Chem. Eur. J. 17 (2011) 5939-5948.

[22] M. Phillips, The chemistry of lignin, Chem. Rev. 14 (1934) 103-170.

[23] W.B. Hewson, H. Hibbert, Studies on lignin and related compounds. LXV. Re-ethanolysis of isolated lignins, J. Am. Chem. Soc. 65 (1943) 1173-1176.

[24] D. Forchheim, J.R. Gasson, U. Hornung, A. Kruse, $\mathrm{T}$. Barth, Modeling the lignin degradation kinetics in an ethanol/formic acid solvolysis approach. Part 2. Validation and transfer to variable conditions, Ind. Eng. Chem. Res. 51 (2012) 15053-15063.

[25] W. Xu, S.J. Miller, P.K. Agrawal, C.W. Jones, Depolymerization and hydrodeoxygenation of switchgrass lignin with formic acid, ChemSusChem 5 (2012) 667-675.

[26] G.H. Tomlinson II, H. Hibbert, Studies on lignin and related compounds. XXV. Mechanism of vanillin formation from spruce lignin sulfonic acids in relation to lignin structure, J. Am. Chem. Soc. 58 (1936) 348-353. 
[27] A.L. Mathias, A.E. Rodrigues, Production of vanillin by oxidation of pine kraft lignins with oxygen, Holzforschung 49 (1995) 273-278.

[28] B.C. Collis for Monsanto Chemicals, Manufacture of vanillin from lignin, CA515266, 1955.

[29] H.-R. Bjørsvik, F. Minisci, Fine chemicals from lignosulfonates. 1. Synthesis of vanillin by oxidation of lignosulfonates, Org. Process. Res. Dev. 3 (1999) 330-340.

[30] A.W. Pacek, P. Ding, M. Garrett, G. Sheldrake, A. W. Nienow, Catalytic conversion of sodium lignosulfonate to vanillin: engineering aspects. Part 1 . Effects of processing conditions on vanillin yield and selectivity, Ind. Eng. Chem. Res. 52 (2013) 8361-8372.

[31] K. Yamamoto, T. Hosoya, K. Yoshioka, H. Miyafuji, H. Ohno, T. Yamada, Tetrabutylammonium hydroxide 30-hydrate as novel reaction medium for lignin conversion, ACS Sustain. Chem. Eng. 5 (2017) 10111-10115.

[32] A. Pineda, A.F. Lee, Heterogeneously catalyzed lignin depolymerization, Appl. Petrochem. Res. 6(2016) 243-256.

[33] R.K. Sharma, N.N. Bakhshi, Catalytic upgrading of pyrolysis oil, Energy Fuel 7 (1993) 306-314.

[34] J. Cho, S. Chu, P.J. Dauenhauer, G.W. Huber, Kinetics and reaction chemistry for slow pyrolysis of enzymatic hydrolysis lignin and organosolv extracted lignin derived from maplewood, Green Chem. 14 (2012) 428-439.

[35] G. Jiang, D.J. Nowakowski, A.V. Bridgwater, Effect of the temperature on the composition of lignin pyrolysis products, Energy Fuel 24 (2010) 4470-4475.

[36] Z.S. Zhan, C. Wang, K. Bi, X. Zhang, C. Yu, R. Dong, L. Ma, C. Pang, Py-GC/MS study of lignin pyrolysis and effect of catalysts on product distribution, Int. J. Agric. Biol. Eng. 10 (5) (2017) 214-225.

[37] T. Ohra-aho, J. Linnekoski, Catalytic pyrolysis of lignin by using analytical pyrolysis-GC-MS, J. Anal. Appl. Pyrolysis 113 (2015) 186-192.

[38] Z. Ma, E. Troussard, J.A. van Bokhoven, Controlling the selectivity to chemicals from lignin via catalytic fast pyrolysis, Appl. Catal. A 423 (2012) 130-136.

[39] -"י.

[40] D.W. Van Krevelen, Graphical-statistical method for the study of structure and reaction processes of coal, Fuel 29 (1950) 269-284.

[41] E.E. Harris, J. D'Ianni, H. Adkins, Reaction of Hardwood lignin with hydrogen, J. Am. Chem. Soc. 60 (1938) 1467-1470.

[42] J.M. Pepper, Y.W. Lee, Lignin and related compounds. I. A comparative study of catalysts for lignin hydrogenolysis, Can. J. Chem. 47 (1969) 723-727.

[43] J.M. Pepper, P. Supathna, Lignin and related compounds. VI. A study of variables affecting the hydrogenolysis of spruce wood lignin using a rhodium-oncharcoal catalyst, Can. J. Chem. 56 (1978) 899-902.
[44] C. Zhao, Y. Kou, A.A. Lemonidou, X. Li, J.A. Lercher, Highly selective catalytic conversion of phenolic biooil to alkanes, Angew. Chem. Int. Ed. 48 (2009) 3987-3990.

[45] X. Zhang, Q. Zhang, L. Chen, Y. Xu, T. Wang, L. Ma, Effect of calcination temperature of $\mathrm{Ni} / \mathrm{SiO}_{2}-\mathrm{ZrO}_{2}$ catalyst on its hydrodeoxygenation of guaiacol, Chin. J. Catal. 35 (2014) 302-309.

[46] C. Zhao, Y. Kou, A.A. Lemonidou, X. Li, J.A. Lercher, Hydrodeoxygenation of bio-derived phenols to hydrocarbons using Raney $\mathrm{Ni}$ and $\mathrm{Nafion} / \mathrm{SiO}_{2}$ catalysts, Chem. Commun. 46 (2010) 412-414.

[47] Y.-C. Lin, C.-L. Li, H.-P. Wan, H.-T. Lee, C.-F. Liu, Catalytic hydrodeoxygenation of guaiacol on Rh-based and sulfided CoMo and NiMo catalysts, Energy Fuel 25 (2011) 890-896.

[48] N. Yan, Y. Yuan, R. Dykeman, Y. Kou, P.J. Dyson, Hydrodeoxygenation of lignin-derived phenols into alkanes by using nanoparticle catalysts combined with Brønsted acidic ionic liquids, Angew. Chem. Int. Ed. 49 (2010) 5549-5553.

[49] Y. Shao, Q. Xia, L. Dong, X. Liu, X. Han, S.F. Parker, Y. Cheng, L.L. Daemen, A.J. Ramirez-Cuesta, S. Yang, Y. Wang, Selective production of arenes via direct lignin upgrading over a niobium-based catalyst, Nat. Commun. 8 (2017).

[50] L. Shuai, M.T. Amiri, Y.M. Questell-Santiago, F. Héroguel, Y. Li, H. Kim, R. Meilan, C. Chapple, J. Ralph, J.S. Luterbacher, Formaldehyde stabilization facilitates lignin monomer production during biomass depolymerization, Science $354 \quad$ (2016) 329-333.

[51] X. Si, F. Lu, J. Chen, R. Lu, Q. Huang, H. Jiang, E. Taarning, J. Xu, A strategy for generating highquality cellulose and lignin simultaneously from woody biomass, Green Chem. 19 (2017) 4849-4857.

[52] H. Konnerth, J. Zhang, D. Ma, M.H.G. Prechtl, N. Yan, Base promoted hydrogenolysis of lignin model compounds and organosolv lignin over metal catalysts in water, Chem. Eng. Sci. 123 (2015) 155-163.

[53] T.H. Parsell, B.C. Owen, I. Klein, T.M. Jarrell, C. L. Marcum, L.J. Haupert, L.M. Amundson, H. I. Kenttamaa, F. Ribeiro, J.T. Miller, M.M. Abu-Omar, Cleavage and hydrodeoxygenation (HDO) of $\mathrm{C}-\mathrm{O}$ bonds relevant to lignin conversion using $\mathrm{Pd} / \mathrm{Zn}$ synergistic catalysis, Chem. Sci. 42 (2013) 806-813.

[54] V. Molinari, C. Giordano, M. Antonietti, D. Esposito, Titanium nitride-nickel nanocomposite as heterogeneous catalyst for the hydrogenolysis of aryl ethers, J. Am. Chem. Soc. 136 (2014) 1758-1761.

[55] R. Shu, Y. Xu, P. Chen, L. Ma, Q. Zhang, L. Zhou, C. Wang, Mild hydrogenation of lignin depolymerization products over $\mathrm{Ni} / \mathrm{SiO}_{2}$ catalyst, Energy Fuel 31 (2017) 7208-7213. 
[56] X. Zhu, L.L. Lobban, R.G. Mallinson, D.E. Resasco, Bifunctional transalkylation and hydrodeoxygenation of anisole over a Pt/HBeta catalyst, J. Catal. 281 (2011) 21-29.

[57] F. Gao, J.D. Webb, H. Sorek, D.E. Wemmer, J.F. Hartwig, Fragmentation of lignin samples with commercial Pd/C under ambient pressure of hydrogen, ACS Catal. 6 (2016) 7385-7392.

[58] Y. Jiang, Z. Li, X. Tang, Y. Sun, X. Zeng, S. Liu, L. Lin, Depolymerization of cellulolytic enzyme lignin for the production of monomeric phenols over Raney $\mathrm{Ni}$ and acidic zeolite catalysts, Energy Fuel 29 (2015) 1662-1668.

[59] Q. Song, F. Wang, J. Cai, Y. Wang, J. Zhang, W. Yu, J. Xu, Lignin depolymerization (LDP) in alcohol over nickelbased catalysts via a fragmentation-hydrogenolysis process, Energy Environ. Sci. 6 (2013) 994-1007.

[60] F.P. Petrocelli, M.T. Klein, Chemical modeling analysis of the yields of single-ring phenolics from lignin liquefaction, Ind. Eng. Chem. Prod. Res. Dev. 24 (1985) 635-641.

[61] K. Barta, G.R. Warner, E.S. Beach, P.T. Anastas, Depolymerization of organosolv lignin to aromatic compounds over $\mathrm{Cu}$-doped porous metal oxides, Green Chem. 16 (2014) 191-196.

[62] L.-P. Xiao, S. Wang, H. Li, Z. Li, Z.-J. Shi, L. Xiao, R.-C. Sun, Y. Fang, G. Song, Catalytic hydrogenolysis of lignins into phenolic compounds over carbon nanotube supported molybdenum oxide, ACS Catal. 7 (2017) 7535-7542.

[63] I.T. Ghampson, C. Sepúlveda, R. Garcia, B.G. Frederick, M.C. Wheeler, N. Escalona, W.J. DeSisto, Guaiacol transformation over unsupported molybdenum-based nitride catalysts, Appl. Catal. A 413-414 (2012) 78-84.

[64] N. Ji, X. Wang, C. Weidenthaler, B. Spliethoff, R. Rinaldi, Iron(II) disulfides as precursors of highly selective catalysts for hydrodeoxygenation of dibenzyl ether into toluene, ChemCatChem 7 (2015) 960-966.

[65] T. Prasomsri, M. Shetty, K. Murugappan, Y. RomanLeshkov, Insights into the catalytic activity and surface modification of $\mathrm{MoO} 3$ during the hydrodeoxygenation of lignin-derived model compounds into aromatic hydrocarbons under low hydrogen pressures, Energy Environ. Sci. 7 (2014) 2660-2669.

[66] H.Y. Zhao, D. Lia, P. Bui, S.T. Oyama, Hydrodeoxygenation of guaiacol as model compound for pyrolysis oil on transition metal phosphide hydroprocessing catalysts, Appl. Catal. A (392) (2011) 305-310.

[67] S. Bhargava, H. Jani, J. Tardio, D. Akolekar, M. Hoang, Catalytic wet oxidation of ferulic acid (a model lignin compound) using heterogeneous copper catalysts, Ind. Eng. Chem. Res. 46 (2007) 8652-8656.

[68] A. Jha, K.R. Patil, C.V. Rode, Mixed Co-Mn oxidecatalysed selective aerobic oxidation of vanillyl alcohol to vanillin in base-free conditions, ChemPlusChem 78 (2013) 1384-1392.
[69] V.R. Mate, M. Shirai, C.V. Rode, Heterogeneous $\mathrm{Co}_{3} \mathrm{O}_{4}$ catalyst for selective oxidation of aqueous veratryl alcohol using molecular oxygen, Catal. Commun. 33 (2013) 66-69.

[70] C. Crestini, M.C. Caponi, D.S. Argyropoulos, R. Saladino, Immobilized methyltrioxo rhenium (MTO) $/ \mathrm{H}_{2} \mathrm{O}_{2}$ systems for the oxidation of lignin and lignin model compounds, Bioorg. Med. Chem. 14 (2006) 5292-5302.

[71] S.K. Badamali, R. Luque, J.H. Clark, S.W. Breeden, Co(salen)/SBA-15 catalysed oxidation of a $\beta-\mathrm{O}-4$ phenolic dimer under microwave irradiation, Catal. Commun. 12 (2011) 993-995.

[72] J. Mottweiler, M. Puche, C. Räuber, T. Schmidt, P. Concepcion, A. Corma, C. Bolm, Copper- and vanadium-catalyzed oxidative cleavage of lignin using dioxygen, ChemSusChem 8 (2015) 2106-2113.

[73] Y. Gao, J. Zhang, X. Chen, D. Ma, N. Yan, A metal-free, carbon-based catalytic system for the oxidation of lignin model compounds and lignin, ChemPlusChem 79 (2014) 825-834.

[74] W. Deng, L. Lin, S. Liu, Oxidative conversion of lignin and lignin model compounds catalyzed by $\mathrm{CeO}_{2}-$ supported Pd nanoparticles, Green Chem. 17 (2015) 5009-5018.

[75] F.G. Sales, L.C.A. Maranhão, N.M. Lima Filho, C.A M. Abreu, Experimental evaluation and continuous catalytic process for fine aldehyde production from lignin, Chem. Eng. Sci. 62 (2007) 5386-5391.

[76] H. Deng, L. Lin, S. Liu, Catalysis of Cu-doped Co-based perovskite-type oxide in wet oxidation of lignin to produce aromatic aldehydes, Energy Fuel 24 (2010) 4797-4802.

[77] J. Zhang, H. Deng, L. Lin, Wet aerobic oxidation of lignin into aromatic aldehydes catalysed by a perovskitetype oxide: $\mathrm{LaFe}_{1-\mathrm{x}} \mathrm{Cu}_{\mathrm{x}} \mathrm{O}_{3}(\mathrm{x}=0,0.1,0.2)$, Molecules 14 (2009) 2747-2757.

[78] X. Gu, K. Cheng, M. He, Y. Shi, Z. Li, La-modified SBA- $15 / \mathrm{H}_{2} \mathrm{O}_{2}$ systems for the microwave assisted oxidation of organosolv beech wood lignin, Maderas Cienc. Tecnol. 14 (2012) 31-42.

[79] M. Dawange, M.V. Galkin, J.S.M. Samec, Selective aerobic benzylic alcohol oxidation of lignin model compounds: route to aryl ketones, ChemCatChem 7 (2015) 401-404.

[80] M.V. Galkin, C. Dahlstrand, J.S.M. Samec, Mild and robust redox-neutral Pd/C-catalyzed lignol b-O- $4^{\prime}$ bond cleavage through a low-energy-barrier pathway, ChemSusChem 8 (2015) 2187-2192.

[81] G.W. Huber, S. Iborra, A. Corma, Synthesis of transportation fuels from biomass: chemistry, catalysts, and engineering, Chem. Rev. 106 (2006) 4044-4098.

[82] G. Centi, P. Lanzafame, S. Perathoner, Analysis of the alternative routes in the catalytic transformation of lignocellulosic materials, Catal. Today 167 (2011) 14-30. 
[83] F. Schüth, R. Rinaldi, N. Meine, M. Käldström, J. Hilgert, M.D. Kaufman Rechulski, Mechanocatalytic depolymerization of cellulose and raw biomass and downstream processing of the products, Catal. Today 234 (2014) 24-30.

[84] A.J. Ragauskas, G.T. Beckham, M.J. Biddy, R. Chandra, F. Chen, M.F. Davis, B.H. Davison, R. A. Dixon, P. Gilna, M. Keller, P. Langan, A. K. Naskar, J.N. Saddler, T.J. Tschaplinski, G. A. Tuskan, C.E. Wyman, Lignin valorization: improving lignin processing in the biorefinery, Science 344 (2014) 1246843.

[85] D. Esposito, M. Antonietti, Redefining biorefinery: the search for unconventional building blocks for materials, Chem. Soc. Rev. 44 (2015) 5821-5835.

[86] R. Rinaldi, R. Jastrzebski, M.T. Clough, J. Ralph, M. Kennema, P.C.A. Bruijnincx, B.M. Weckhuysen, Paving the way for lignin valorisation: recent advances in bioengineering, biorefining and catalysis, Angew. Chem. Int. Ed. 55 (2016) 8164-8215.

[87] L. Hodasova, M. Jablonski, A. Skulcova, A. Haz, Lignin, potential products and their market value, Wood Res. 60 (2015) 973-986.

[88] M.-R. de Valladares, Global Trends and Outlook for Hydrogen, IEA Hydrogen Technology Collaboration Program, 2017. 20 pp.
[89] https://www.methanex.com/our-business/pricing (Consulted December 2017).

[90] https://www.statista.com (Consulted December 2017).

[91] A.J.J. Straathof, A. Bampouli, Potential of commodity chemicals to become bio-based according to maximum yields and petrochemical prices, Biofuels Bioprod. Biorefin. 11 (2017) 798-810.

[92] F. Cavani, S. Albonetti, F. Basile, Aromatics from biomasses: technological options for chemocatalytic transformations, in: F. Cavani, S. Albonetti, F. Basile, A. Gandini (Eds.), Chemicals and Fuels From Bio-Based Building Blocks, Wiley-VCH, Weinheim, 2016, pp. 33-50.

[93] J.-P. Lange, Catalysis for biorefineries - performance criteria for industrial operation, Catal. Sci. Technol. 6 (2016) 4759-4767.

[94] G. Rødsrud, M. Lersch, A. Sjöde, History and future of world's most advanced biorefinery in operation, Biomass Bioenergy 46 (2012) 46-59.

[95] S. Venkatesan, Adsorption, in: S. Ramaswamy, H.J. Huang, B.V. Ramarao (Eds.), Separation and Purification Technologies in Biorefineries, Wiley, New York, 2013, pp. 101-148.

[96] A.A. Kiss, J.-P. Lange, B. Schuur, D.W.F. Brilman, A.G. J. van der Ham, S.R.A. Kersten, Separation technology. Making a difference in biorefineries, Biomass Bioenergy 95 (2016) 296-309. 


\title{
Non-Print Items
}

\begin{abstract}
Lignocellulosic biomass offers a unique resource for the sustainable production of bio-derived chemicals and fuels in replacement of the fossil products. Lignin, a major component of biomass is largely underexploited, mainly due to its recalcitrant molecular structure which hinders the development of depolymerization techniques. Considering its rich phenolic functionalities in lignin, catalytic transformations can render lignin a viable source of value-added chemicals. The present contribution aims to highlight the emerging heterogeneous depolymerization strategies, challenges and economic viability aspects of pyrolysis, reduction and oxidation processes.
\end{abstract}

Keywords: Biomass, Lignin, Heterogeneous catalysis, Depolymerization, Biorefinery 